\title{
Urbanismo comercial em Phoenix: um estudo de quatro formatos comerciais no Arizona
}

\author{
Commercial urbanism in Phoenix, AZ: a study of four commercial formats in \\ Arizona
}

Carlos José Lopes Balsas

University at Albany, New York, United States of America

\section{Resumo}

A relação entre as atividades comerciais e o crescimento das cidades já vem de longa data. No decorrer dos tempos, essa relação resultou em diferentes formatos comerciais e foi mais ou menos espontânea ou planejada consoante as necessidades das pessoas, as tecnologias de produção e de distribuição, as técnicas de armazenamento e venda e a capacidade de inovação das sociedades. A área metropolitana de Phoenix, no Estado do Arizona, Estados Unidos, é um caso de estudo interessante pela sua rápida e recente evolução na construção de uma mistura de formatos tradicionais, modernos e pós-modernos, assim como pelas transformações e adaptações decorrentes da crise financeira global de 2008. Este estudo revê as características de quatro formatos comerciais na área metropolitana de Phoenix (o mercado público de Phoenix, um lifestyle center em Scottsdale, o centro comercial Tempe Market Place em Tempe e uma área comercial no terminal quatro do aeroporto internacional Sky Harbor) e discute um conjunto de quatro ilações para o futuro do urbanismo comercial no mundo ocidental: local-global; material-imaterial; essencial-dispensável e autêntico-ilusório.

Palavras-chave: Urbanismo. Comércio. Regeneração. Arizona, EUA.

\section{Abstract}

The flourishing of commerce has always influenced the development and growth of cities. Overtime, this relationship has given rise to the emergence of spontaneous and planned commercial formats, depending on people's needs, technologies of production and distribution, sale and storage techniques and the technical innovation of firms. The Phoenix metropolitan area in Arizona is a complex case study due to its recent commercial developments with a mix of modern and postmodern formats and the transformations and adaptations resulting from the 2008 global financial crisis. This paper analyzes the characteristics of four commercial formats in the Phoenix metropolitan area (the Phoenix public market, a "lifestyle center" in Scottsdale, the Tempe Market Place in Tempe, and the commercial area of Sky Harbor's terminal 4) and discusses a set of four implications for the future of commercial developments in the western world: local - global, material - sensorial, essential - dispensable, and authentic - illusory.

Keywords: Urbanism. Commerce. Regeneration. Arizona, USA.

CJLB é Ph.D., professor auxiliar, Geografia e Planeamento, e-mail: cbalsas@albany.edu 


\section{Introdução}

A relação entre as atividades comerciais e o crescimento das cidades já vem de longa data (Chung et al., 2002). No decorrer dos tempos, essa relação resultou em diferentes formatos comerciais e foi mais ou menos espontânea ou planejada consoante as necessidades das pessoas, as tecnologias de produção e de distribuição, as técnicas de armazenamento e venda e a capacidade de inovação das sociedades (Balsas, 2003; DeLisle, 2005). A área metropolitana de Phoenix, no Estado do Arizona, Estados Unidos, é um caso de estudo importante pela sua rápida e recente evolução na construção de um conjunto de formatos tradicionais, modernos e pós-modernos (Cachinho, 2006), assim como pelas transformações e adaptações decorrentes da crise financeira global de 2008 . 0 objetivo deste estudo é analisar comparativamente as características de quatro formatos comerciais na área metropolitana de Phoenix e discutir um conjunto de quatro ilações para o futuro do urbanismo comercial no mundo ocidental: local-global, material-imaterial, essencialdispensável e autêntico-ilusório.

Este texto está organizado em cinco partes: na primeira, reveem-se as distinções principais entre urbanismo e planejamento comercial na Europa e nos Estados Unidos; na segunda, faz-se uma caracterização da evolução da área metropolitana de Phoenix; na terceira, apresentam-se sumariamente os quatro formatos comerciais em análise; na quarta, discutem-se comparativamente as características dos quatro centros (ano, localização, conceito, acessibilidade, funções, organização e tipos de espaços interiores, lojas, centralidade pedonal, tipos de gestão, ilações principais em termos de inovação e níveis de sucesso); na quinta parte, faz-se uma síntese conclusiva de quatro dilemas principais subjacentes a esses novos formatos comerciais.

\section{Urbanismo ou planejamento comercial?}

As cidades europeias cresceram e evoluíram ao longo de muitos séculos. Esse crescimento orgânico criou um tipo de cidade onde os formatos tradicionais do mercado público e da loja deram lugar a grandes armazéns e a centros comerciais (Gaspar, 1987). Em muitos países europeus, o aparecimento desses novos formatos comerciais em áreas de expansão levou ao declínio dos formatos tradicionais localizados no centro das cidades (Balsas, 2003). Em outros casos, observou-se uma coexistência saudável entre os vários formatos devido, principalmente, a intervenções públicas coletivas, de modo a valorizar culturas e práticas endógenas (Vargas \& Castilho, 2006). Esses procedimentos são vistos por alguns autores como limitações ao funcionamento dos mercados. Outros autores defendem tais práticas como uma justificativa para a preservação de estilos de vida, práticas culturais e manutenção de cidades aprazíveis (Balsas, 2002; Balsas, 2003; Carrizo \& Gardon, 2003).

Nos Estados Unidos, onde as cidades são muito mais recentes, os formatos comerciais evoluíram de uma forma relativamente mais rápida do que na Europa (Robertson, 1997; Crawford, 2002; Wall, 2005). Para alguns autores, os efeitos positivos são visíveis no acesso a uma gama muito diversificada de produtos por um número relativamente elevado de consumidores (Balsas, 2001). Para outros autores, esses novos formatos comerciais geram uniformidade e homogeneidade nas cidades, o que é um detrimento para a habitabilidade urbana (Goss, 1993; Halebsky, 2004).

A questão fundamental coloca-se na necessidade de uma gestão das atividades comerciais enquanto influenciadoras da qualidade de vida urbana (Vargas \& Castilho, 2006). 0 urbanismo comercial nos países europeus é feito mais em função das necessidades coletivas do que individuais. Nos Estados Unidos, uma lógica de eficiência econômica que sobrepõe o indivíduo ao coletivo tem levado à criação de formatos tipificados e de fácil reprodução.

Enquanto na Europa parecem existir níveis elevados de participação pública capazes de gerar ganhos para a sociedade no seu todo, nos Estados Unidos os novos formatos comerciais são propostos pelos investidores e consumidos pelos cidadãos, sem uma grande atenção aos efeitos indiretos desses mesmos empreendimentos (Balsas, 2001; Scharoun, 2012). Na Europa, o urbanismo comercial parece ser mais enraizado nas culturas locais; nos Estados Unidos, o planejamento comercial é visto mais como um sistema de regras que permite o funcionamento de uma economia global com rebatimentos locais relativamente acentuados, dependendo dos contextos de crescimento ou de declínio urbanos e regionais (Mappin \& Allmendinger, 2000; Loukaitou-Sideris, 2002; Balsas 2003). 
No que diz respeito ao planejamento comercial dos terminais de aeroporto, Kasarda (2008, p. 52) afirma que esses locais são bastante privilegiados como locais de compras porque os seus utilizadores têm níveis de rendimento, em média, três a cinco vezes superiores às médias nacionais, enquanto os volumes de passageiros são também muito superiores aos que tradicionalmente se deslocam a um dado centro comercial - cerca de 88 milhões anuais, em contraste com os 8-12 milhões de visitantes anuais a um centro comercial regional. 0 mesmo autor defende que o volume de negócios nas lojas dos aeroportos pode ser até seis vezes mais do que nos tradicionais locais de venda em ambientes citadinos. Para além do comércio varejista, Graham (2009) realça ainda a importância relativa do aluguel de automóveis e os estacionamentos como duas fontes importante de receitas nos aeroportos, sobretudo, norte-americanos.

Por último, uma vaga recente de revitalização de mercados públicos e feiras semanais, ao estilo farmers market, em muitos países europeus e nos Estados Unidos, está contribuindo para a gentrificação ou nobilitação comercial de muitos bairros citadinos (Gonzalez \& Waley, 2012).

\section{Phoenix, Arizona}

A área metropolitana de Phoenix é um exemplo paradigmático do crescimento de baixa densidade com características expansivas, baseado em centros polinucleados, moradias unifamiliares e com uma grande dependência do automóvel para grandes e pequenas deslocações (Figura 1). 0 surgimento da área metropolitana de Phoenix remonta à passagem para o século XX e a sua evolução urbana foi relativamente lenta até a Segunda Guerra Mundial (Gammage, 2003). No centro da cidade, localizavam-se os diferentes tipos de comércio, os edifícios públicos, as sedes dos bancos e outros tipos de serviços normalmente encontrados em localizações centrais (Sertich, 1980).

Com o passar dos anos, a cidade cresceu com base em uma malha retilíneo-ortogonal. 0 primeiro centro comercial fora da área histórica (Park Central) foi construído na Avenida Central de Phoenix, o que

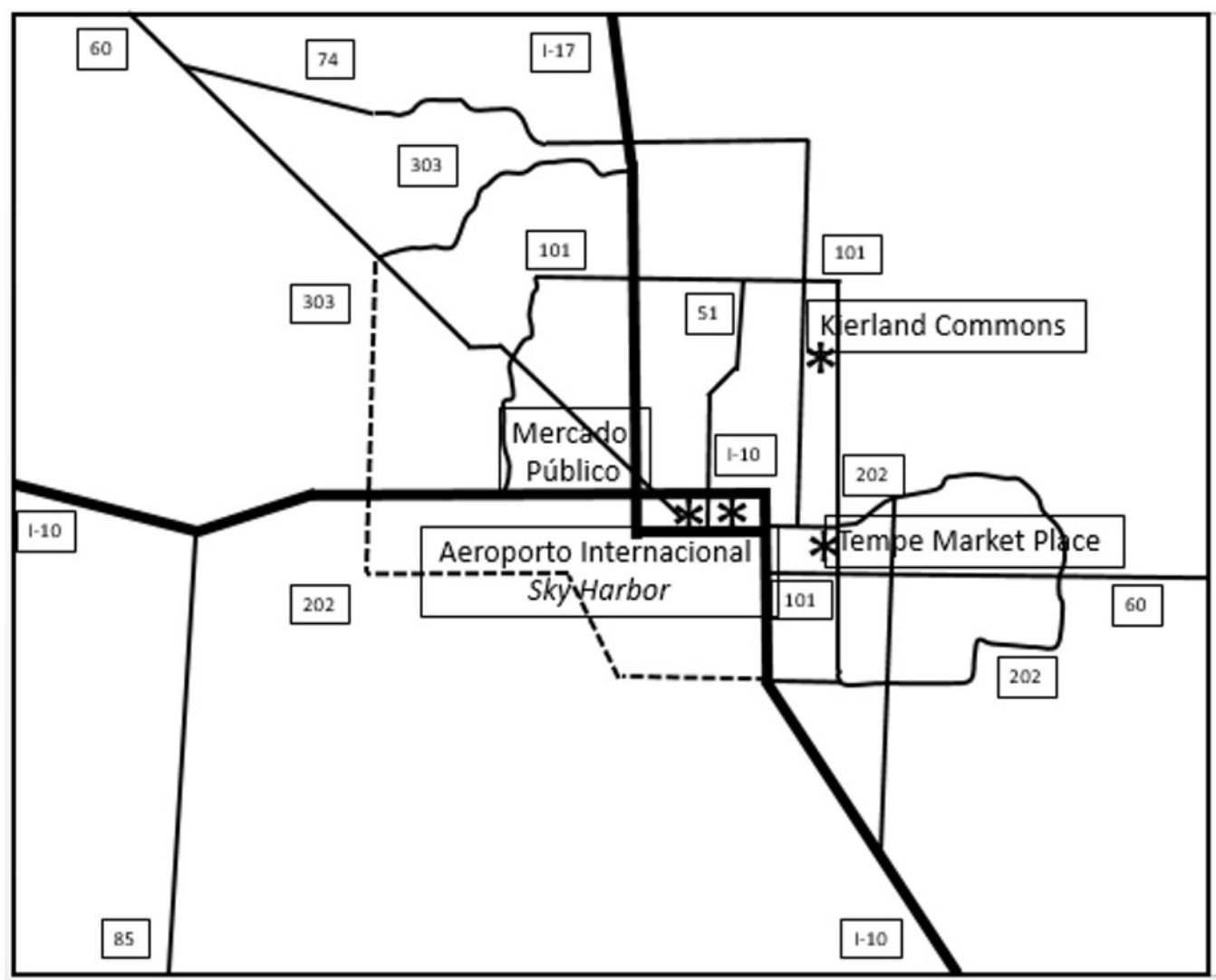

Figura 1 - Localização dos formatos comerciais na área metropolitana de Phoenix, Arizona, Estados Unidos Nota: Redesenhado pelo autor com base em cartografia de Maricopa Association of Governments. 
levou à expansão da cidade, da sua área financeira e de serviços para fora do centro tradicional. Essa estrutura viária deu origem à maximização das localizações comerciais nas interseções das vias principais da cidade. Devido à elevada acessibilidade de automóveis, o formato de praça comercial em L nos quatro cantos das interseções é utilizado no planejamento das áreas comerciais mais como um elemento de projeto econômico e menos como um elemento de desenho e forma urbana (Collins, 2005).

0 crescimento da cidade de Phoenix foi quase explosivo, passando de cerca de 100 mil habitantes em 1950 para 1,4 milhão no ano 2010.0 crescimento da área metropolitana foi ainda mais impressionante, passando de cerca de 330 mil para 3,8 milhões de habitantes em 2010 (Wu et al., 2011). As razões desse crescimento urbano foram, principalmente, a existência de solo urbanizável, a distribuição eficiente de água, um clima ameno por cerca de oito meses, a existência de empregos e um fluxo constante de emigrantes (Collins, 2005). É claro que esse crescimento urbano teve algumas consequências menos positivas, como é o caso da destruição do deserto de Sonora, a extinção de fauna e flora e todos os impactos relacionados com um forte crescimento urbano em um curto espaço de tempo: poluição ambiental, desenvolvimento expansivo, congestionamentos em horário de pico etc. (Gober, 2006; Ross, 2011).

No âmbito de planejamento urbano e ao longo dos anos, a cidade de Phoenix utilizou centros comerciais como elementos marcantes das paisagens urbanas e como subcentros das suas áreas de expansão. A ideia das urban villages era criar centros autônomos que suprissem as necessidades dos residentes dessas novas áreas em termos de emprego e necessidades diárias. Os centros comerciais iniciais funcionaram relativamente bem para o abastecimento das necessidades diárias, mas foram ao declínio devido à construção de outros centros comerciais em outras localizações mais periféricas. Dois exemplos dessas duas situações são o centro antigo de Maryvale na parte oeste e o centro comercial Paradise Village na parte norte de Phoenix (Sertich, 1980).

À medida que a cidade de Phoenix cresceu, novos centros comerciais foram construídos em áreas de expansão (Garreau, 1992). Esse fenômeno influenciou o declínio do centro da cidade de Phoenix, o que era bem visível até alguns anos atrás. Entre os aspectos mais visíveis, contava-se o número de edifícios devolutos, que, com o abandono das diversas atividades centrais, resultaram em áreas empobrecidas e em lotes de solo urbano abandonados (Schmandt, 1995). Os residentes que ficaram nas imediações do centro viram as suas ofertas comerciais ficarem bastante reduzidas. Esse fenômeno ficou conhecido como o aparecimento dos food deserts.

A construção de uma série de projetos de revitalização urbana no centro da cidade - entre os quais um centro de convenções, complexos esportivos, hotéis e, mais recentemente, um novo campo universitário da Universidade Estadual do Arizona (ASU), além de uma série de empreendimentos de uso misto habitacional, comercial e de serviços, assim como o reinício de um mercado público na área central contribuiu para a revitalização do centro da cidade (Gober, 2006; Ehrenhalt, 2012).

No entanto, o crescimento do número de novos centros comerciais com diferentes tipologias nos vários municípios da área metropolitana foi muito elevado (Hackworth, 2007; ÓhUallacháin \& Leslie, 2013). Aglomerados do lado leste, como Scottsdale, Gilbert, Mesa, Chandler, e do lado oeste, como Surprise, Glendale, Buckeye e Avondale, construíram muitos e em diversos formatos comerciais a partir da década de 1990 (Romero, 2004; Johnson, 2008). Esses novos empreendimentos têm sido construídos na proximidade de vias de comunicação rápidas, como autoestradas e circulares da área metropolitana (Arizona Town Hall, 2009).

A geografia dos centros comerciais na área metropolitana inclui os seguintes empreendimentos por ordem de abertura: do centro para a periferia, Park Central em Phoenix, Spectrum Mall (inicialmente chamado de Chris-Town Mall) e Phoenix Metro Center, ambos em Phoenix, Fiesta Mall na cidade de Mesa, Fashion Square no centro de Scottsdale, Phoenix Desert Sky Mall no extremo oeste de Phoenix; na periferia norte, Towne Center e Desert Ridge; na periferia sul, o Chandler Mall na cidade de Chandler; na reserva de índios nativos no sopé da Montanha Sul de Phoenix, o Outlet Mall Center. Muitos desses centros comerciais de escala regional recebem cerca de 100 milhões de visitas por ano (Magahern, 2004, p. 20).

É interessante ainda notar que alguns centros comerciais foram fechados (dead-malls), mas apenas muito recentemente foram reconvertidos para outras funções, tais como o Los Arcos Mall em South Scottsdale, onde está instalado agora o novo campo tecnológico da ASU, denominado Sky Song.

A área metropolitana de Phoenix foi gravemente afetada pela crise global financeira de 2008, o que levou a uma recentralização do desenvolvimento 
urbano na cidade de Phoenix e na área mais central da metrópole. A construção da linha do metrô de superfície em 2008 serviu para alterar a localização de novos empreendimentos habitacionais e comerciais, além dos padrões e tipologias de desenvolvimento. Por exemplo, o aumento do número de transitoriented developments (TOD) em áreas circundantes às estações do metrô de superfície, incluindo na Avenida Central de Phoenix, Avenida Van Buren e Avenida Apache em Tempe, foi realmente notável.

Outra alteração importante recente na estrutura da cidade de Phoenix foi a demolição de uma praça central localizada entre as Avenidas Jefferson e Washington e a construção do empreendimento de uso misto denominado Cityscape. Essa alteração levou à criação de um novo espaço cívico muito mais moderno e dinâmico, abrangendo o novo campo da ASU. O Cityscape, construído nos anos de 2000, é um complexo de uso misto com comércio varejista, entretenimento, hotelaria e duas torres de escritórios. No entanto, o novo campo universitário contemplou a renovação de edifícios existentes para salas de aula e a construção de novos dormitórios, o que poderá aumentar a população residente no centro da cidade em cerca de 15 mil novos habitantes.

As obras de expansão e a remodelação do centro de convenções em Phoenix foram também muito importantes para a recentralização das atividades de serviços no centro da cidade. Essas obras contribuíram grandemente para o aumento do número, incluindo os novos Sheraton, Westin, Palomar, Hilton Resort e o Renaissance - estes dois últimos estão localizados em edifícios históricos renovados recentemente.

A revitalização de dois bairros no centro da cidade de Phoenix - bairro das artes (arts district) e o bairro industrial (wharehouse district) - contribuiu para o aumento da visibilidade das atividades comerciais e lúdicas na área central. 0 primeiro incluiu as Avenidas Central, Roosevelt e Grand Avenue; o segundo contemplou a área ao sul das arenas de basquete (Talking Sticks Resort Arena) e beisebol (Chase Field).

Finalmente, para além dessas novas ações de planejamento urbano, é possível observar também os novos complexos habitacionais e de serviços construídos em 2014 e 2015 em áreas centrais da cidade de Tempe, não necessariamente localizados ao longo da linha do metrô de superfície, mas com importantes aspectos locativos, tais como as áreas de expansão ao longo do Rio Salado, do parque Papago no lado sudeste e ainda do próprio centro da cidade de Tempe.

O Quadro 1 mostra as características do mercado varejista na área metropolitana de Phoenix no primeiro

Quadro 1 - Estatísticas do mercado varejista

\begin{tabular}{|l|c|c|c|c|c|}
\hline \multicolumn{1}{|c|}{ Mercado } & $\begin{array}{c}\text { Área rentável } \\
\text { (square feet) }\end{array}$ & $\begin{array}{c}\text { Percentagem } \\
\text { devoluta (\%) }\end{array}$ & $\begin{array}{c}\text { Rácio de } \\
\text { absorção* } \\
\text { (square feet) }\end{array}$ & $\begin{array}{c}\text { Em } \\
\text { construção } \\
\text { (square feet) }\end{array}$ & $\begin{array}{c}\text { Preço de } \\
\text { aluguel \$ } \\
\text { USD/square feet }\end{array}$ \\
\hline Paradise Valley & 7.951 .668 & 8,8 & 25.644 & 0 & 24,20 \\
\hline Maricopa & 528.488 & 4,1 & $(4.799)$ & 0 & 21,64 \\
\hline North Scottdale & 15.383 .538 & 7,9 & 84.387 & 0 & 20,79 \\
\hline East Phoenix & 3.519 .823 & 6,9 & 76.731 & 0 & 18,52 \\
\hline Sun City & 9.058 .042 & 8,4 & 25.622 & 103.000 & 16,45 \\
\hline Apache Junction & 4.795 .732 & 6,8 & $(33.708)$ & 64.497 & 15,74 \\
\hline Metropolitan Phoenix & 148.834 .624 & 10,0 & 387.226 & 176.997 & 15,64 \\
\hline Northwest Phoenix & 12.463 .737 & 15,9 & 60.615 & 0 & 15,09 \\
\hline North Bell Road & 15.811 .858 & 8,9 & 8.299 & 0 & 14,54 \\
\hline Tempe / Ahwatukee & 17.938 .367 & 6,8 & 81.251 & 0 & 14,93 \\
\hline Scottsdale & 4.531 .560 & 7,2 & 83 & 0 & 14,84 \\
\hline West-Southwest Phoenix & 19.200 .808 & 7,7 & 60.703 & 0 & 14,81 \\
\hline Mesa / Chandler / Gilbert & 37.651 .003 & 14,4 & 2.398 & 9.500 & 14,38 \\
\hline
\end{tabular}

Fonte: CBRE (2014).

*0 rácio de absorção explica a área comercial varejista transacionada em proporç̃õo ao total da área comercial na unidade geográfica de base à análise. 
trimestre de 2014. É bem evidente o abrandamento relativo do mercado em uma grande parte da área metropolitana, assim como os preços mais elevados em zonas relativamente nobres e de rendas mais elevadas, como nas zonas de Paradise Valley e em North Scottsdale. Para além dos empreendimentos referidos, a porcentagem de espaços comerciais devolutos tem se mantido bastante alta desde o início da crise em 2008.

\section{Quatro formatos comerciais}

Os formatos comerciais escolhidos para uma análise mais detalhada foram todos construídos e/ou renovados na década de 2000. Eles são: o mercado público de Phoenix; o lifestyle center em Phoenix, chamado Kierland Commons; o centro comercial Tempe Market Place na cidade de Tempe; o centro comercial no terminal quatro do aeroporto Sky Harbor em Phoenix. Apesar de terem características relativamente diferentes, esses espaços comerciais possuem um objetivo comum, que é a compra e venda de bens e serviços a consumidores e clientes com características diversas.

\section{Mercado público}

O mercado está localizado na área central da cidade de Phoenix, a alguns quarteirões ao norte do antigo centro cívico da cidade. Ao contrário dos emblemáticos mercados abastecedores nas cidades europeias como Barcelona, Lisboa, Viena etc., os mercados públicos nas cidades da América do Norte entraram em declínio e muitos desapareceram há algum tempo. Honráveis exceções são os mercados de Seattle e de Los Angeles (PPS, 1996). 0 mercado público em Phoenix ocorria uma vez por semana, aos sábados; posteriormente também às quartas-feiras; mais recentemente transitou temporariamente para um edifício específico (Burwell, 2007).

Nesse mercado vendem-se produtos agrícolas, vegetais, compotas, peças de arte, roupas etc. A ênfase principal é nos produtos orgânicos, na qualidade e no atendimento personalizado que é dispensado no ato de compra e venda. A presença de bandas musicais no recinto do mercado foi utilizada para cativar pessoas e criar uma atmosfera de bem-estar e descontração. 0 mercado é gerido por uma organização não governamental (Community Food Connections). 0 número limitado de pessoas que se deslocam ao centro condiciona a sua expansão.

\section{Kierland commons}

Este centro comercial representa uma diferenciação forte com as tipologias comerciais construídas na área metropolitana nas décadas anteriores. Essas tipologias eram, sobretudo, centradas em três ou quatro lojas-âncoras, completamente cobertas, com ar-condicionado, rodeadas de amplos parques de estacionamento. 0 Kierland Commons tem um formato completamente diferente devido ao seu conceito de rua principal, com uma praça e uma fonte no centro do empreendimento, estacionamento ao longo das ruas e por trás das lojas, amplos passeios para pedestres e, acima de tudo, uma mistura de funções comerciais, residenciais e de serviços, em uma área com 15,8 hectares.

\section{Tempe market place}

Este centro comercial mostra a necessidade que as cidades no centro da área metropolitana têm de proceder a estratégias de consolidação urbana. Ele foi construído em uma área relativamente abandonada, mas com uma localização muito boa, perto de duas autoestradas principais, o anel rodoviário 101 e 202. 0 conceito comercial incluiu a conjugação de dois tipos de espaços comerciais, a tradicional praça comercial urbana com as lojas abertas para os parques de estacionamento e um distrito pedestre com comércio especializado, restaurantes, cinemas etc. Esse formato comercial utiliza arte pública em diferentes localizações dentro do centro e um conjunto múltiplo de eventos para atrair consumidores.

\section{Aeroporto Internacional Sky Harbor}

0 aeroporto internacional Sky Harbor em Phoenix teve mais de 40 milhões de passageiros em 2011 (Allett, 2012). Os espaços comerciais no aeroporto oferecem aos consumidores uma oportunidade para fazer uma compra de ocasião antes de saírem 
de Phoenix. Esse espaço funciona quase como uma "última" oportunidade para adquirir uma lembrança da cultura local.

Esse formato é muito diferente dos outros três revistos anteriormente, no sentido de que as pessoas não se deslocam ao aeroporto para fazer as suas compras, a não ser que trabalhem lá ou sejam voluntárias. Nesses casos não incorrem em despesas adicionais com estacionamento e ainda recebem um desconto nas suas compras em algumas lojas (MJ, 2008). Todos os três terminais do aeroporto possuem estabelecimentos comerciais e de serviços, mas o terminal quatro é o que tem a maior concentração de estabelecimentos comerciais. Presentemente, o terminal três está em obras de expansão e remodelação que devem estar concluídas em 2020.

\section{Estudo comparativo}

O Quadro 2 faz uma síntese das principais características desses quatro formatos comerciais em análise. As características são o ano de construção, a localização, o conceito, a acessibilidade, as funções, a organização e o tipo de espaços interiores, as lojas, a centralidade pedonal e o tipo de gestão. 0 Quadro 3 apresenta as ilações principais em termos de inovação e os níveis de sucesso desses formatos comerciais.

Quadro 2 - Estudo comparativo dos quatro formatos comerciais

\begin{tabular}{|c|c|c|c|c|}
\hline & Public Market & Kierland Commons & Tempe Market Place & $\begin{array}{c}\text { Aeroporto Sky } \\
\text { Harbor }\end{array}$ \\
\hline Ano & 2004 & 2000 & 2007 & $\begin{array}{l}\text { Terminal quatro renovado em } \\
2004\end{array}$ \\
\hline Localização & Centro de Phoenix & $\begin{array}{c}\text { Cidade de Phoenix e subúrbio } \\
\text { de Scottsdale }\end{array}$ & $\begin{array}{c}\text { Canto nordeste da cidade de } \\
\text { Tempe }\end{array}$ & $\begin{array}{c}\text { Em Phoenix, no centro da área } \\
\text { metropolitana }\end{array}$ \\
\hline Conceito & Mercado público & $\begin{array}{l}\text { Centro comercial estilo de vida } \\
\text { (lifestyle) }\end{array}$ & Centro comercial regional & Centro comercial especializado \\
\hline Acessibilidade & $\begin{array}{c}\text { De carro, transportes } \\
\text { públicos, a pé e de bicicleta, } \\
\text { estacionamento adjacente para } \\
\text { automóvel }\end{array}$ & $\begin{array}{l}\text { Principalmente de automóvel, } \\
\text { estacionamento para automóvel } \\
\text { em garagens e de superfície }\end{array}$ & $\begin{array}{l}\text { De carro, transportes públicos, } \\
\text { de bicicleta, estacionamento de } \\
\text { superfície nas áreas centrais }\end{array}$ & $\begin{array}{l}\text { Principalmente de carro e por } \\
\text { meio de transportes públicos, } \\
\text { estacionamento para automóvel } \\
\text { em garagem }\end{array}$ \\
\hline Funções & Comercial e de lazer & $\begin{array}{c}\text { Comercial, de lazer, de serviços } \\
\text { e habitação }\end{array}$ & $\begin{array}{c}\text { Principalmente comercial e } \\
\text { de lazer }\end{array}$ & Comercial e de lazer \\
\hline Lojas ${ }^{\star}$ & $\begin{array}{l}194 \text { vendedores, dos quais } \\
38 \text { agricultores, } 13 \text { produtos } \\
\text { domésticos e de pele, } \\
43 \text { produtos artesanais, } 3 \text { de } \\
\text { serviços, } 27 \text { caminhões de } \\
\text { comidas pré-preparadas, } \\
70 \text { vendedores de comida) }\end{array}$ & $\begin{array}{l}81 \text { comércios e serviços, dos } \\
\text { quais } 4 \text { de acessórios e malas, } \\
29 \text { de vestuário e calçado, } \\
12 \text { de oculista, joalheria e } \\
\text { especialidade, } 5 \text { de saúde e } \\
\text { beleza, } 5 \text { de produtos para } \\
\text { casa, } 17 \text { restaurantes, } 9 \text { de } \\
\text { serviços e escritórios }\end{array}$ & $\begin{array}{c}111 \text { comércios e serviḉs, } \\
\text { dos quais } 32 \text { de vestuário e } \\
\text { acessórios, } 5 \text { de diversões, } \\
26 \text { restaurantes e bares, } 9 \text { de } \\
\text { calcado e desporto, } 26 \text { de } \\
\text { produtos de casa e pessoais, } \\
13 \text { de saúde e necessidades } \\
\text { de beleza }\end{array}$ & $\begin{array}{l}123 \text { comércios e serviços no } \\
\text { terminal quatro (antes e depois } \\
\text { das portas de embarque), } \\
\text { dos quais } 48 \text { restaurantes, } \\
38 \text { serviços e } 37 \text { comércios }\end{array}$ \\
\hline Interiores & $\begin{array}{l}\text { Inicialmente tendas } \\
\text { temporárias, espaços públicos e } \\
\text { edifício permanente }\end{array}$ & $\begin{array}{c}\text { Espaços pedestres exteriores } \\
\text { e ajardinamento de espaços } \\
\text { públicos }\end{array}$ & $\begin{array}{l}\text { Espaços de circulação e } \\
\text { parqueamento de automóvel, } \\
\text { com excepão da área pedestre } \\
\text { de lazer }\end{array}$ & $\begin{array}{l}\text { Espaços públicos pedestres } \\
\text { internos }\end{array}$ \\
\hline $\begin{array}{c}\text { Centralidade pedonal } \\
\text { - walkscore } \\
(0-100)^{\star \star}\end{array}$ & $\begin{array}{l}91 \text { (paraíso pedonal / walker's } \\
\text { paradise) }\end{array}$ & $\begin{array}{c}63 \text { (algo pedonal / somewhat } \\
\text { walkable) }\end{array}$ & $\begin{array}{l}42 \text { (Dependência Automóvel / } \\
\text { car-dependent) }\end{array}$ & $\begin{array}{c}46 \text { (Dependência Automóvel / } \\
\text { car-dependent) }\end{array}$ \\
\hline Gestão & Não governamental & Privada & Privada & Pública \\
\hline
\end{tabular}

*Dados relativos a 2014-2015.

**Consulta realizada em 6 de janeiro 2016.

Fontes: CFC (2014) e diretórios de lojas disponíveis nos respectivos empreendimentos comerciais. 
Quadro 3 - Estudo comparativo das ilações decorrentes dos formatos comerciais

\begin{tabular}{|c|c|c|c|c|}
\hline & Public Market & Kierland Commons & Tempe Market Place & $\begin{array}{c}\text { Aeroporto Sky } \\
\text { Harbor }\end{array}$ \\
\hline llações & $\begin{array}{l}\text {-É uma primeira tentativa para } \\
\text { eliminar a existência de food deserts } \\
\text { em Phoenix } \\
\text { - } 0 \text { sucesso futuro depende dos } \\
\text { demais projetos de revitalização } \\
\text { urbana no centro da cidade }\end{array}$ & $\begin{array}{l}\text { - É visto como uma inovação no con- } \\
\text { texto regional dos espaços comerciais } \\
\text { existentes } \\
\text { - } 0 \text { sucesso demonstra que espaços } \\
\text { bem planejados ao ar livre, além da } \\
\text { mistura de funç̃óes, são benéficos } \\
\text { para a experiência comercial }\end{array}$ & $\begin{array}{l}\text { - É visto como uma inovação capaz } \\
\text { de conjugar os tradicionais centros } \\
\text { comerciais com espaços pedestres de } \\
\text { lazer e recreio } \\
\text { - } 0 \text { sucesso inicial está relacionado } \\
\text { à proximidade com as autoestradas } \\
\text { e à localização central na área } \\
\text { metropolitana }\end{array}$ & $\begin{array}{l}\text { - Tem um nicho de mercado único } \\
\text { que não oferece competição a outros } \\
\text { formatos comerciais, com exceção do } \\
\text { destino turístico Old Town Scottsdale } \\
\text { - O sucesso desse formato está ligado } \\
\text { ao tempo disponível para fazer } \\
\text { compras e à autenticidade da cultura } \\
\text { local e estadual }\end{array}$ \\
\hline
\end{tabular}

Fonte: Elaborado pelo autor.

A construção e a revitalização desses formatos comerciais são muito recentes. As lojas no terminal quatro do aeroporto começaram a ser renovadas em 2004 (Sunnucks, 2004). Com exceção do centro comercial em Scottsdale, a localização dos outros três espaços comerciais é no centro da área metropolitana de Phoenix. 0 mercado público mostra um retorno ao centro da cidade também evidenciado em outras cidades norte-americanas (Stearns, 2004).

Ações deliberadas de planejamento e de revitalização urbana são, em parte, responsáveis pelo aparecimento do mercado público e dos outros projetos de revitalização urbana no centro da cidade de Phoenix. Em termos de conceito comercial, a realização do mercado público no centro de Phoenix mostra uma valorização das dimensões públicas da cidade e uma aposta na criação de espaços mais habitáveis para quem prefere, por razões várias, viver no centro, mesmo que estas sejam ainda, por enquanto, relativamente diferentes das cidades mais vibrantes do nordeste dos Estados Unidos e do sul da Europa.

Os conceitos-base dos outros três formatos comerciais são praticamente novos em Phoenix. A localização do lifestyle center no norte de Phoenix, em uma localização adjacente à cidade de Scottsdale, parece tirar partido do uso do solo nas imediações do aeroporto e da sua área financeira e de negócios (Leinberger, 2008; Yan \& Eckman, 2009). As lojas de marca atraem uma clientela com elevado poder de compra. No entanto, 0 Tempe Market Place, com a sua mistura de cadeias de franchise e de lojas e restaurantes menos conhecidos, atrai um grupo mais eclético de consumidores, entre os quais muitos alunos e pessoal do campo da ASU em Tempe. Finalmente, as lojas do aeroporto atraem pessoas que se encontram em viagem ou pessoas que foram acompanhar viajantes e aproveitam para fazer compras, principalmente, por impulso.

A boa acessibilidade a esses formatos comerciais surge como uma mais-valia e como um dos aspectos que influencia não só a sua localização, mas a sua viabilidade futura enquanto investimento comercial. Infelizmente, por causa da grande dependência do automóvel no Estado do Arizona, particularmente em Phoenix, o Kierland Commons e o Tempe Market Place ficaram localizados na proximidade de autoestradas e de vias principais. Os congestionamentos durante as horas de pico nas autoestradas das imediações do centro de Phoenix podem ser vistos como uma limitação ao sucesso da revitalização do centro da cidade.

Contudo, a construção de uma linha de metrô de superfície que liga as cidades de Mesa, Tempe e Phoenix parece garantir deslocações alternativas e relativamente rápidas, cômodas e diretas no centro da área metropolitana. Uma vez que esse metrô de superfície já tem uma ligação com o aeroporto Sky Harbor, é possível que consumidores se desloquem ao aeroporto de transporte público e que o caráter desse espaço comercial possa mudar e ficar mais diverso e apelativo não apenas para aqueles que estão de viagem, mas também para aqueles que o querem utilizar como um espaço de comércio e lazer.

O Kierland Commons é o único formato dos quatro selecionados que combina funções residenciais com comerciais e de serviços. 0 aspecto lúdico e de lazer é uma característica comum a todos os empreendimentos, se bem que com nuances diferentes (Kunzmann, 2011). A restauração está presente no Kierland Commons, no Tempe Market Place e nos vários terminais do Sky Harbor. A presença de salas 
de cinema no Tempe Market Place atrai uma grande clientela que vai assistir a filmes e depois resolve visitar as lojas, os restaurantes e os bares localizados no centro comercial. A presença de galerias de arte e de museus é também uma constante em três desses espaços, incluindo no aeroporto.

O Quadro 2 mostra a composição comercial e de serviços nos quatro empreendimentos em análise. Verifica-se a existência da mesma percentagem (36\%) de estabelecimentos de vestuário e calçado no Kierland Commons e no Tempe Market Place. No que concerne a restaurantes e bares, o mercado público e o aeroporto possuem percentagens relativamente mais elevadas (40-50\%) do que os outros dois empreendimentos, com apenas $21-23 \%$ dos estabelecimentos relativos a esse ramo comercial.

É ainda de se destacar a grande concentração de estabelecimentos dedicados à venda de produtos para a casa, pessoais, de saúde e de beleza no Tempe Market Place, com 44\% do total de lojas. Esse valor elevado resulta da conjugação de dois tipos diferenciados de estabelecimentos, os de menores dimensões localizados na zona pedonal (com áreas de cerca de $200 \mathrm{~m}^{2}$ ) e os maiores do tipo big box (de 12.500 a $16 \mathrm{mil} \mathrm{m}^{2}$ ) com amplo estacionamento no exterior das respectivas lojas.

Finalmente, é importante salientar a localização e o número diferenciado dos restaurantes no terminal do aeroporto antes e depois da passagem pelos serviços de segurança e identificação. As áreas de embarque (A, B, C e D) possuem 36 restaurantes, ao contrário dos apenas 11 localizados na área comum do terminal quatro.

A organização interna dos centros é relativamente diferente. 0 mercado público no centro de Phoenix é constituído por tendas temporárias em uma localização provisória. 0 caráter improvisado desse espaço comercial tende a atrair consumidores com um espírito pioneiro, que procuram algo diferente não oferecido nos supermercados dos subúrbios. 0 centro comercial no subúrbio de Scottsdale, com as suas ruas citadinas dentro de um empreendimento privado, é um exemplo inovador de mistura de funções urbanas com ganhos - neste caso, particular--, principalmente, para o proprietário do centro comercial e, de um modo indireto, para a as cidades de Phoenix e de Scottsdale no seu todo.

O Tempe Market Place combina áreas destinadas a automóveis e a pedestres. Os arquitetos utilizaram elementos decorativos e materiais com elementos naturais, como o fogo e a água. Fontes e lareiras podem ser encontradas no distrito pedestre, assim como as emblemáticas palmeiras, que, apesar de serem muito esguias, não dão sombra aos transeuntes. Por último, as áreas comerciais do aeroporto são feitas com materiais nobres e caros. Esse pormenor mostra talvez a intenção dos arquitetos em quererem deixar uma boa impressão na mente de todos aqueles que passam pelo aeroporto a caminho de outras paragens (Kasarda \& Lindsay, 2011).

Outra característica desses empreendimentos comerciais é a sua centralidade pedonal diferenciada. Com recurso do programa Walkscore, é possível verificar que ambas as localizações do Tempe Market Place e do aeroporto internacional Sky Harbor têm uma pontuação típica de áreas bastante dependentes do automóvel, enquanto a localização do Kierland Commons é considerada como pedonal. Finalmente, a localização do mercado público no centro da cidade garante-lhe uma pontuação pedonal bastante elevada - e até mesmo a designação de paraíso pedonal.

A gestão desses formatos comerciais vai de uma parceria público-privada no caso do mercado público, passando pela propriedade e gestão privada nos casos dos centros de Scottsdale e do Tempe Market Place, até a uma gestão pública, mas bastante profissionalizada pela cidade de Phoenix, no caso do aeroporto.

Em termos de ilações, podemos deduzir que o mercado público é uma primeira tentativa para eliminar a existência de food deserts em Phoenix. O sucesso futuro desse espaço comercial depende do sucesso dos outros projetos de revitalização urbana no centro da cidade (Stone, 2007). O Triângulo das Descobertas (Discovery Triangle) é uma nova iniciativa de desenvolvimento comunitário com objetivos múltiplos, incluindo: (1) uma estratégia de desenvolvimento territorial destinada a propiciar negócios e reconversão de solo urbano por meio da recentralização - infill development (Talen, 2011); para isso, há a proximidade do centro das cidades de Phoenix e Tempe, assim como dos seus dois campos universitários e do aeroporto internacional Sky Harbor; (2) suprir a falta de supermercados que forneçam alimentos frescos e vegetais às populações menos beneficiadas por meio de um serviço de busmobile, que contemple a utilização de um veículo para distribuir e vender produtos alimentícios em áreas empobrecidas no centro de Phoenix. 
É possível constatar que o formato do mercado público teve bastante sucesso em Phoenix, o que levou à sua imitação recente com a criação do Uptown Farmers Market. Este é localizado a alguns quilômetros de distância ao norte da atual localização, no adro e parque de estacionamento de uma das megaigrejas (North Phoenix Baptist Church), na área conhecida como North Phoenix, ainda no alinhamento da Avenida Central e ao norte da Avenida Camelback. Esse mercado público, com mais de 60 tendas e vendedores ambulantes, teve início em 2014 e, paralelamente ao Phoenix Public Market, ocorre também aos sábados de manhã.

0 Kierland Commons em Scottsdale é visto como uma inovação no contexto regional dos espaços comerciais existentes e o seu sucesso parece mostrar que espaços bem planejados e ao ar livre, assim como a mistura de várias funções, são benéficos para a experiência comercial. 0 sucesso desse centro comercial levou em grande parte à construção recente do Scottsdale Quarter em uma localização adjacente ao Kierland Commons, apenas do outro lado da rua. Esse empreendimento comercial, aberto ao público em 2009, representa uma tentativa de capitalização na subentralidade criada pelo Kierland Resort and Spa e pelo Kierland Commons. Ele consiste em 11,3 hectares, $34 \mathrm{mil} \mathrm{m}^{2} \mathrm{de}$ comércios e restaurantes, e $19 \mathrm{mil} \mathrm{m}^{2}$ de escritórios. A tipologia de uso misto comercial de escritórios e de habitação é inovadora para a área. A sua arquitetura sofisticada, paisagismo e beleza natural típica do deserto do Arizona apelam a uma clientela de gama média e média alta. 0 parque habitacional adjacente Crescent Scottsdale Quarter compreende 1 hectare e contempla unidades habitacionais de luxo.

A subcentralidade criada pelo Kirland Commons e pelo Scottsdale Quarter representa a concretização do modelo proposto por Leinberger (2008, p. 35-37) no livro The Option of Urbanism, quando o autor se refere ao conceito do favored quarter - muito mais amplo é certo, mas, de qualquer modo, evidenciado pela elevada concentração de oferta comercial, infraestrutura e boa acessibilidade.

O Tempe Market Place é visto como uma inovação capaz de conjugar os tradicionais centros comerciais com espaços pedestres de lazer e de recreio. O sucesso inicial está relacionado à proximidade com as autoestradas e à localização central na área metropolitana. 0 aeroporto tem um nicho de mercado único que não oferece grande competição com outros formatos comerciais, com exceção do destino turístico conhecido como Old Town Scottsdale. 0 sucesso desse formato está ligado ao tempo disponível para fazer compras e à autenticidade da cultura local e estadual (Rowley \& Slack, 1999; Berry, 2007).

\section{Discussão conclusiva}

O principal objetivo deste estudo era rever as características de quatro formatos comerciais na área metropolitana de Phoenix, os quais foram escolhidos por representarem diferentes conceitos e inovações recentes na paisagem comercial de Phoenix. No início do século XXI, o sucesso das atividades comerciais parece ser baseado nas experiências que os indivíduos retiram delas e nos sentimentos que elas criam nos consumidores (Kowinski, 1985; Pine \& Gilmore, 1999; Rigby, 2011).

Alguns autores argumentam que as atividades comerciais atingiram um tal grau de especialização que manipulam as sensações dos cidadãos em uma espiral de consumo, quase infindável e com consequências menos positivas para alguns grupos da sociedade (Baudrillard, 1998; Barber, 2007; Bolin et al., 2013). Se bem que há questões subjacentes ao modelo capitalista que fomentam essa espiral e que a mente humana tem capacidades igualmente únicas que parece garantir uma constante adaptação a situações adversas. No contexto desta pequena incursão pelos espaços comerciais na cidade de Phoenix, há quatro dilemas que merecem algumas considerações: 1) local-global; 2) material-imaterial; 3) essencial-dispensável e 4) autêntico-ilusório.

O dilema entre a escala local e a global aparece nos dias de hoje como algo que confunde e ao mesmo tempo maravilha os consumidores locais habituados a comprar objetos produzidos a milhares de quilômetros de distância (Santos, 2013). Exemplos desse dilema são as latas de atum vendidas pelo próprio latoeiro com um tempero especial do Estado de Washington, ou o molho de bife com sabor de abrunho feito pelo próprio vendedor no Estado do Texas, ou ainda os dream catchers indígenas feitos em países do Extremo Oriente e vendidos aos turistas em algumas lojas dos terminais do aeroporto Sky Harbor como autênticos. Exemplos semelhantes podem ser encontrados nas lojas dos outros dois centros comerciais, por exemplo: as largas dezenas de vinhos, cervejas e bebidas alcoólicas 
de praticamente todo o mundo que podemos encontrar na loja Bevmo ou os mais variados produtos na loja World Market no Tempe Market Place.

0 dilema entre as realidades materiais e imateriais pode ser observado nos produtos que levamos para casa e que são comprados com dinheiro (ou, mais frequentemente, com cartões de débito/crédito) e as experiências que "vivemos" no ato de procura e de compra. Essas sensações são intensificadas por projetistas, os quais aplicam fórmulas previamente testadas de modo a fazer com que os consumidores passem mais tempo nos centros comerciais e gastem mais dinheiro em compras.

0 terceiro dilema diz respeito à distinção entre o que é essencial e o que é dispensável. Na categoria do essencial, encontramos produtos e experiências que permitem a nossa existência física e espiritual. A pirâmide das necessidades de Maslow permite hierarquizar necessidades humanas e as nossas tolerâncias físicas e psicológicas, em um contínuo que vai do mais tangível ao dispensável. É claro que, nos quatro formatos comerciais analisados neste texto, encontramos produtos essenciais, mas também muitos outros que são dispensáveis pela falta de valor emocional ou de possível utilização futura.

Finalmente, o último dilema diz respeito aos valores da autenticidade e do ilusório ou imaginário individual e/ou coletivo (Schmookler, 1993; Pile, 2005). A área metropolitana de Phoenix, tal como muitas outras cidades e metrópoles norte-americanas, possui uma cultura eclética e relativamente nova, onde o que é autêntico é, algumas vezes, motivo de orgulho - como os aspectos culturais relacionados com o Southwest, o deserto de Sonora e os cowboys - e, em outros casos, é motivo de incompreensão e desdém - como os maus-tratos aos índios nativos dessa parte dos Estados Unidos.

As relações entre as cidades e as suas áreas comerciais têm evoluído de modos diferentes e de acordo com diferentes sistemas de regulação (Guy, 2007), consoante as normas legais e valores culturais das várias épocas (Smiley, 2002; Salgueiro \& Cachinho, 2007). Nos Estados Unidos, o formato do centro comercial nas suas diferentes nuances atingiu níveis técnicos quase dignos de uma "ciência" comercial (Goss, 1993; Barber, 2007). 0 que parece faltar a essa "ciência" é a razão do ato da compra (Sandel, 2012), a legitimação de práticas comerciais sem ética, a demonstração de níveis crescentes de respeito por culturas locais próximas e longínquas e a resolução dos quatro dilemas identificados anteriormente. A crise financeira global de 2008 levou a um abrandamento e à recentralização do desenvolvimento urbano em áreas mais centrais da região metropolitana de Phoenix, assim como a uma demonstração mais premente com questões relacionadas ao ambiente, à sustentabilidade e à resiliência urbana (Meunier, 2012; Sheridan, 2015). O conceito de economia solidária que começa a ser popularizado no Brasil e em outros países, com visões de cidadania alternativas ao modelo de desenvolvimento ocidental, parece apresentar algumas respostas interessantes (Vásquez, 2002; Gaiger, 2004).

\section{Referências}

Allett, T. (2012). More than a makeover. Airports International, 45(7), 34-36.

Arizona Town Hall. (2009). From here to there: transportation opportunities for Arizona. Tucson: Arizona Town Hall.

Balsas, C. (2001). Building dreams of mass-consumption across the Atlantic, a comparative study of two mega malls. Passages: Journal of Transnational and Transcultural Studies, 3(2), 137-162. http://dx.doi.org/10.1163/156916701753477759.

Balsas, C. (2002). Urbanismo comercial e parcerias públicoprivado: ensinamentos da experiência estrangeira. Lisboa: GEPE.

Balsas, C. (2003). Urbanismo comercial: mitos e boas práticas na revitalização de centros urbanos. Sociedade e Território: Revista de Estudos Urbanos e Regionais, 36, 116-130.

Barber, B. (2007). Consumed: how markets corrupt children, infantilize adults, and swallow citizens whole. New York: Norton.

Baudrillard, J. (1998). The consumer society: myths and structures. London: Sage.

Berry, J. (2007). Sky Harbor study to look at diversity of vendors. The Arizona Republic, 25 de setembro de 2007.

Bolin, B., Declet-Barretto, J., Hegmon, M., Meierotto, L., \& York, A. (2013). Double exposure in the Sunbelt: the sociospatial distribution of vulnerability in Phoenix, Arizona. In C. Boone, \& M. Fragkias (Eds.), Urbanization and sustainability: linking urban ecology, environmental justice and global environmental change (p. 159-178). Heidelberg: Springer. http://dx.doi.org/10.1007/978-94-007-5666-3_10. 
Burwell, S. (2007). The downtown Phoenix public market. Java Magazine, 12-13 de maio de 2007.

Cachinho, H. (2006). Consumactor: da condição do indivíduo na cidade pós-moderna. Finisterra: Revista Portuguesa de Geografia, XLI(81), 33-56.

Carrizo, I. \& Gardon, P. (2003). Regulacion comercial basada en cuotas de mercado. Boletin Económico de ICE, 2787, 23-34.

Chung, C., Inaba, J., Koolhaas, R. \& Leong, T. (2002). Harvard Design School guide to shopping. New York: Taschen.

Collins, W. (2005). The emerging metropolis: Phoenix, 19441973. Phoenix: Arizona State Parks Board.

Commercial Real Estate Services - CBRE (2014). Phoenix retail marketview Q1-2014. Los Angeles: CBRE.

Community Food Connections - CFC. (2014). Community Food Connections 2014 annual report. Medicine Hat: CFC. Recuperado em 6 de Janeiro de 2016, de http://phxpublicmarket. com/openair/wp-content/uploads/2013/10/2014-CFCAnnual-Report-web-version.pdf

Crawford, M. (2002). Suburban life and public space. In D. Smiley (Ed.), Sprawl and public space: redressing the mall (p. 21-30). Washington, D.C.: National Endowment for the Arts.

DeLisle, J. (2005). The evolution of shopping centre research: a 12-year retrospective. Journal of Shopping Center Research, 12(2), 1-83.

Ehrenhalt, A. (2012). The great inversion and the future of the American city. New York: Alfred A Knopf.

Gaiger, L. (2004). A economia solidária no Brasil e o sentido das novas formas de produção não capitalistas. Revista Venezolana de Economía Social, 8, 9-37.

Gammage, G., Jr. (2003). Phoenix in perspective: reflections on developing the desert. Tempe: HCDE-ASU.

Garreau, J. (1992). Edge City, life on the new frontier. New York: First Anchor Books.

Gaspar, J. (1987). Do pelourinho ao centro comercial. Povos e Culturas, 2, 243-259.

Gober, P. (2006). Metropolitan Phoenix, place making and community building in the desert. Filadélfia: University of Pennsylvania Press.

Gonzalez, S., \& Waley, P. (2012). Traditional retail markets: the new gentrification frontier? Antipode, 45(4), 965-983.. http://dx.doi.org/10.1111/j.1467-8330.2012.01040.x.
Goss, J. (1993). The "magic of the mall:" an analysis of form, function, and meaning in the contemporary retail built environment. Annals of the Association of American Geographers, 83(1), 18-47.. http://dx.doi. org/10.1111/j.1467-8306.1993.tb01921.x.

Graham, A. (2009). How important are commercial revenues to today's airports? Journal of Air Transport Management, 15(3), 106-111.. http://dx.doi.org/10.1016/j. jairtraman.2008.11.004.

Guy, C. (2007). Planning for retail development. Londres: Routledge.

Hackworth, J. (2007). Neoliberal city: Governance, ideology, and development in American urbanism. Ithaca: Cornell University Press.

Halebsky, S. (2004). Superstores and the politics of retail development. City \& Community, 3(2), 115-134.. http:// dx.doi.org/10.1111/j.1535-6841.2004.00072.x.

Johnson, A. (2008). Wary developers use caution. The Arizona Republic, 51, 24 de fevereiro de 2008.

Kasarda, J. (2008). Shopping in the Airport City and Aeropolis. Research Review, 15(2), 50-56.

Kasarda, J., \& Lindsay, G. (2011). Aerotropolis: the way we'll live next. New York: Farrar, Straus and Giroux.

Kowinski, W. (1985). The malling of America: an inside look at the great consumer paradise. New York: W. Morrow.

Kunzmann, K. (2011). Spaces of consumption. In T. Banerjee, \& A. Loukaitou-Sideris (Eds.), Companion to Urban design (p. 391-404). Nova Iorque: Routledge.

Leinberger, C. (2008). The option of Urbanism. Washington, D.C.: Island Press.

Loukaitou-Sideris, A. (2002). Regeneration of urban commercial strips: Ethnicity and space in three Los Angeles neighborhoods. Journal of Architectural and Planning Research, 19(4), 334-350.

Magahern, J. (2004). Big Time Mallin': living, loving and loathing in the mini-cities of the valley's malls. Phoenix New Times, 9 de dezembro de 2004. Recuperado em 10 de julho de 2016, de http://www.phoenixnewtimes.com/ news/big-time-mallin-6396951

Mappin, G., \& Allmendinger, P. (2000). Retail development. In P. Allmenddinger, \& J. Raemaekers (Eds.), Introduction to planning practice (p. 191-214). Chichester: John Wiley \& Sons. 
Meunier, J. (2012). Making desert cities sustainable. In K. Pijawka, \& M. Gromulat (Eds.), Understanding sustainable cities: concepts, cases, and solutions (p. 107-124). Dubuque: Kendall Hunt.

MJ (2008). Interview by Carlos Balsas. Phoenix, 1 março 2008.

ÓhUallacháin, B., \& Leslie, T. (2013). Spatial pattern and order in sunbelt retailing: shopping in Phoenix in the twenty-first century. The Professional Geographer, 65(3), 396-420.. http://dx.doi.org/10.1080/00330124.2012.6 81587.

Pile, S. (2005). Real cities: modernity, space and the phantasmagorias of city life. London: Sage.

Pine, J., \& Gilmore, J. (1999). The experience economy: work is theatre and every business a stage. Boston: Harvard Business School Press.

Project for Public Spaces - PPS. (1996). Public markets and community revitalization. Washington, D.C.: The Urban Land Institute.

Rigby, D. (2011). The future of shopping. Harvard Business Review, 89(12), 65-76.

Robertson, K. (1997). Downtown retail revitalization: a review of American development strategies. Planning Perspectives, 12(4), 383-401.. http://dx.doi.org/10.1080/026654397364591.

Romero, C. (2004). A mall for the future. The Arizona Republic, 53, 17 setembro 2004.

Ross, A. (2011). Bird on Fire: lessons from the world's least sustainable city. Oxford: Oxford University Press.

Rowley, J., \& Slack, F. (1999). The retail experience in airport departure lounges: reaching for timelessness and placelessness. International Marketing Review, 16(4/5), 363-376. http://dx.doi.org/10.1108/02651339910281901.

Salgueiro, T. \& Cachinho, H. (2007). As relações cidade: comércio: dinâmicas de evolução e modelos interpretativos (Apontamentos de Geografia: Série Investigação, No. 20). Lisboa: Centro de Estudos Geográficos.

Sandel, M. (2012). What money can't buy: the moral limits of markets. New York: Farrar, Straus and Giroux.

Santos, M. (2013). Profetas do consumo: amanhã é o primeiro dia do nosso sonho de consumo. Lisboa: Âncora.

Scharoun, L. (2012). America at the mall: the cultural role of a retail utopia. Jefferson: McFarland \& Co.
Schmandt, M. (1995). Postmodern Phoenix. Geographical Review, 85(3), 349-363.. http://dx.doi.org/10.2307/215278.

Schmookler, A. (1993). The illusion of choice: how the market economy shapes our destiny. Albany: State University of New York Press.

Sertich, R. (1980). Comparative analysis of regional shopping centers in the Phoenix, Arizona planning area (Tese de Mestrado não publicada). Tempe: Arizona State University.

Sheridan, M. (2015). Special section retail. Urban Land, 74(11/12), 107-114.

Smiley, D., (Ed.). (2002). Sprawl and public space, redressing the mall. Washington, D.C.: National Endowment for the Arts.

Stearns, J. (2004). Public market set to open in Phoenix. The Arizona Republic, 3, 30 de setembro de 2004.

Stone, J. (2007). Fate of Phoenix, feeding Phoenix's (hopeful) economic boom. 944TM Magazine, 128, paginação.

Sunnucks, M. (2004). Sky Harbor Terminal 4 to expand retail offerings. The Business Journal of Phoenix, $7 \mathrm{de}$ março de 2004.

Talen, E. (2011). Sprawl retrofit: sustainable urban form in unsustainable places. Environment and Planning. B, Planning \& Design, 38(6), 952-978.. http://dx.doi. org/10.1068/b37048.

Vargas, H., \& Castilho, A. (2006). Intervenções em centros urbanos, objectivos, estratégias e resultados. Barueri: Editora Manole.

Vásquez, E. (2002). Principles of solidarity economics. Recuperado em 2 de Março de 2008, de http://www. jesuit.ie/ijnd/SolidarityEconomics.pdf

Wall, A. (2005). Victor Gruen: from urban shop to new city. Barcelona: Actar.

Wu, J., Jenerette, G., Buyantuyev, A., \& Redman, C. (2011). Quantifying spatiotemporal patterns of urbanization: the case of the two fastest growing metropolitan regions in the United States. Ecological Complexity, 8(1), 1-8. http:// dx.doi.org/10.1016/j.ecocom.2010.03.002.

Yan, R., \& Eckman, M. (2009). Are lifestyle centres unique? Consumers' perceptions across locations. International Journal of Retail \& Distribution Management, 37(1), 24-42. http://dx.doi.org/10.1108/09590550910927144.

Recebido: Ago. 05, 2015

Aprovado: Mar. 22, 2016 